\title{
Exploring the bidirectional relationship between chronic disease and depression among female Syrian refugees and Jordanians: a qualitative analysis
}

Madison Sharp, ${ }^{1}$ Janine Kara, ${ }^{2}$ Salma Almidani, ${ }^{2}$ Mamoun Ahram, ${ }^{3}$ Refqi Mahmoud ${ }^{4}$ and Kaveh Khoshnood ${ }^{2}$

${ }^{1}$ Yale School of Medicine, New Haven, Connecticut, United States of America. ${ }^{2}$ Department of Epidemiology of Microbial Diseases, Yale School of Public Health, New Haven, Connecticut, United States of America (Correspondence to: Kaveh Khoshnood: kaveh.khoshnood@yale.edu). ${ }^{3}$ Department of Physiology and Biochemistry, University of Jordan School of Medicine, Amman, Jordan. ${ }^{4}$ Division of Cardiovascular Disease, Jordanian Ministry of Health, Amman, Jordan.

\begin{abstract}
Background: Nearly 700 ooo Syrian refugees currently reside in Jordan. Chronic disease and neuropsychiatric conditions are leading contributors of morbidity among refugee and host communities. The bidirectional relationship between depression and chronic disease is not well studied among displaced Syrian or Jordanian women.

Aims: This qualitative study explores the bidirectional relationship between chronic illness and comorbid depression, as well as related themes, among Jordanian and Syrian women with known chronic disease-populations that receive medical care through distinct and evolving health care structures - to assist providers and policy makers in creating culturally sensitive interventions.

Methods: Forty Jordanian women and Syrian refugees with chronic disease were interviewed at four clinical settings in Amman, Jordan. Data collection occurred from June-August 2017. Content analysis was completed with Dedoose, a qualitative coding software.

Results: The majority of Syrian women endorsed a relationship between their chronic disease and depression. Some women felt too depressed to take medication for chronic conditions, while others felt depression contributed to chronic illnesses. Syrian women reported less perceived social support than Jordanian women. Although some Syrians were unable to afford medications, they reported fewer negative health care experiences than Jordanians. Both populations endorsed female-specific hardships impacting their mental health, including the demands of motherhood, household duties, and marital strife.
\end{abstract}

Conclusion: This study explores the intersection of depression and chronic disease among Syrian and Jordanian women. By documenting stressors and experiences accessing health care, mental health and chronic disease interventions can be integrated and tailored to these populations.

Keywords: refugees, chronic illness, comorbid depression, Jordan, Syrian

Citation: Sharp M; Kara J; Almidani S; Ahram M; Mahmoud R; Khoshnood K. Exploring the bidirectional relationship between chronic disease and depression among female Syrian refugees and Jordanians: a qualitative analysis. East Mediterr Health J. 2021;27(12):1153-1161. https://doi.org/10.26719/ emhj.21.017

Received: 11/10/19; accepted: 07/06/20

Copyright (C) World Health Organization (WHO) 2021. Open Access. Some rights reserved. This work is available under the CC BY-NC-SA 3.o IGO license (https://creativecommons.org/licenses/by-nc-sa/3.o/igo).

\section{Introduction}

\section{Background}

The Syrian civil war has resulted in one of the most catastrophic refugee crises in modern history, with an estimated 5.6 million people displaced due to the conflict (1). According to the United Nations High Commissioner of Refugees (UNHCR), 664330 refugees have settled in Jordan; the majority live in urban areas outside camps, with women representing $23.4 \%$ of the 18 -59-years age group (1).

The influx of Syrian refugees into Jordan has prevented its once robust health care system from keeping up with demand (2). Refugee populations have been shown to have high prevalence of chronic diseases attributable to a lack of access to appropriate care and adequate medication (3). A 2014 survey found that $43 \%$ of all Syrian refugee households in Jordan had at least one family member diagnosed with a noncommunicable disease (NCD) (4). Jordanians have also experienced an increase in NCDs consistent with the epidemiological transition from communicable diseases (5).

The relationship between chronic disease and depressive symptoms is not well-established among female Syrian refugees or Jordanians. Arab women have a higher reported depression prevalence than Arab men and are less likely to utilize mental health services $(6,7)$. Women in Jordan live with traditional societal standards that can often be coupled with gender discrimination and violence, thereby exacerbating depressive symptoms. Sociodemographic factors are significant contributors to the expression of mental illness; for instance, Jordanian women with low income have been reported as having twice the rate of psychiatric morbidity compared with the 
rest of the population (8). There is a strong emphasis on economic status as an indicator of psychiatric morbidity in Jordanian women, particularly among those living in urban areas (8).

Due to the increasing burden of NCDs and depression faced by displaced and local women, we undertook this study to better understand the bidirectional relationship between depression and chronic disease among female Jordanians and Syrian refugees.

\section{Objectives}

We sought to explore the bidirectional relationship between comorbid physical and mental health disorders as well as related themes among female Jordanian and Syrian refugees with known chronic disease. This study aimed to identify similarities and differences in the experiences of Syrian and Jordanian women, populations that receive medical care through distinct and evolving health care structures, to assist providers and policy-makers in creating culturally sensitive interventions to prevent and treat comorbid depression and NCDs.

\section{Methods}

\section{Data collection}

This research was part of a larger study that recruited 272 female Syrian refugees and Jordanians of child-bearing age with chronic disease from 4 clinics and hospitals across Amman, Jordan (Sharp MB, Parpia AS, Ahram M, Mahmoud R, Khoshnood K. Prevalence of and risk factors for depression among female Syrian refugees and Jordanians with chronic disease: a pilot study. East Mediterr Health J. In press). The selected sites represent sites of medical care for underserved Jordanians and Syrians. Health care-seeking behaviour differs between Jordanians and Syrians due to financial barriers and access constraints.

In our previous study we compared demographic and health characteristics by nationality and depression level and identified predictors of depression via multivariable ordinal regression. Depression severity was identified using the Patient Health Questionnaire-9, a multipurpose instrument for screening and diagnosing depression severity. From the participants in our previous study, we randomly interviewed 20 Jordanian women and 20 Syrian women for the current study. Data were collected from June to August 2017.

\section{Interview}

To ensure homogenous data collection and reduce errors, a female Jordanian interpreter conducted semi-structured interviews that lasted less than 20 minutes. The interview was created with the intention of addressing gaps in the literature regarding the intersection of depression and chronic disease (see semistructured interview guide below).

- For Syrian refugees: Could you tell me your story?

- How did you come here from Syria?
- What were the circumstances that brought you to Jordan?

- For Syrian refugees: How has your experience been in Jordan so far?

- Could you tell me about your experiences visiting health clinics or hospitals?

- How is the quality of health care you receive?

- Please tell me about your understanding of mental health and depression.

- Have you been diagnosed with depression by a doctor?

- Are there certain things that make you feel depressed or sad?

- Have you noticed any relationship between your chronic disease (for example, high blood pressure, diabetes, colitis, etc.) and when you feel depressed?

- If you are depressed, do you think your chronic disease impacts your depression?

- For example, if you do not have adequate access to health services to treat your chronic disease, do this make you feel depressed?

- Could you provide other examples of your chronic disease impacting your depression?

- If you are depressed, do you think your depression impacts your chronic disease?

- For example, think about instances when you did not take your chronic disease medications-could you tell me what was going on and how you felt?

- Could you provide other examples of your depression impacting your chronic disease?

- Do you think there are factors specific to being female that make women depressed?

- If so, what do you think they are?

- Could you tell me about your experiences at health clinics/hospitals related to your depression?

- Have you told your family and friends about your depressive symptoms?

- Do you feel as if you have received support?

- Do you take any medications?

- If so, what are they?

- Do you take anything for your depression?

- For example, medication, herbal remedies?

- What do you do when you feel depressed?

- For example, do you sleep more, go on a walk, eat more, etc.?

- If you feel depressed or sad, why do you think you feel this way?

- Could you explain your symptoms when you feel depressed?

- How long do they last for? 
- Is there anything that makes your symptoms disappear or makes you feel better?

- If you are depressed, does your depression affect your mind, your body, both, or neither?

Responses were recorded and transcribed into English. Inclusion criteria were: being a female Jordanian or a female Syrian refugee who arrived in Jordan no more than 6 years ago; receiving medical care at a clinic or hospital in Amman; having at least one chronic disease; and aged 18-50 years. Pregnant women were excluded. Participants were recruited using convenience sampling.

\section{Ethics}

Ethical approval was obtained from the Yale Human Subjects Committee, the Jordanian Ministry of Health, Caritas Jordan, Noor Al-Hussein Foundation, and Jordan University Hospital.

\section{Data analysis}

Data analysis was carried out using Dedoose, version 8.2, a qualitative coding software. Content analysis was used to identify the main categories extrapolated from the transcripts (9). Content analysis is commonly used in public health qualitative research (10). The analysis for this study followed the 5 -step approach of Pope et al. (11): a broad familiarization with the data (for example, listening to interview recordings while reading and writing transcripts), identifying key themes emerging from the data, creating an index for the data based on the thematic framework, which was done using Microsoft Excel, rearranging the data and interpreting the findings.

\section{Results}

\section{Overview}

The analysis generated 5 categories: stressors influencing depression, perceived social support for depressive symptoms, access to and quality of health care, the bidirectional relationship between chronic disease and depression, and female-specific hardships related to depression. Two additional categories, migration rationale and positive experiences in Jordan, were generated for Syrian women. The content of certain categories is described through subcategories.

Jordanian women were on average aged 36 years, married, living with 5 family members, had attended college and owned their home. In comparison, Syrian women were on average 40 years old, married, living with 6 family members, had completed primary or preparatory school and rented their home. Quotations to support recurring themes identified through data analysis are included in Tables 1 and 2.

\section{Migration rationale}

\section{Syrian}

Syrian women reported several reasons for immigration to Jordan, including family members, a need for medical care and a desire for safety. Two women reported that they had a family member living in Jordan, and one shared her belief that Jordan treated Syrians better than Lebanon. Eight women disclosed that they emigrated for medical assistance, including prenatal care, care for their sick or disabled children, or lack of access to medications in Syria. Most of the Syrian women reported that their main immigration rationale was seeking safety and refuge (Table 1). They reported that their houses

\begin{tabular}{|c|c|}
\hline Theme & Quotation \\
\hline Migration rationale and story & $\begin{array}{l}\text { "We left Syria looking for safety; I came with my husband and my children and I was pregnant. We came to } \\
\text { Za'atari camp and we stayed for } 15 \text { days then we came to Amman because my husband's brother was here. We } \\
\text { were in Homs where there were killings, bombings and raping. We were scared and we left Syria to be safe." } \\
\text { "We came here legally. I was in Aleppo and there was war and we couldn't live there." }\end{array}$ \\
\hline Stressors & $\begin{array}{l}\text { "Our economic situation (the rent of the home, water, electricity); my husband is sick." } \\
\text { "When I think about my children's future." }\end{array}$ \\
\hline Positive experiences in Jordan & $\begin{array}{l}\text { "It's good; we get all the services, education, health services." } \\
\text { "It's not our own country but we attempt to fit in." }\end{array}$ \\
\hline Perceived social support & $\begin{array}{l}\text { "I don't tell anyone [about my depression]." } \\
\text { "I tell my family [about my depression]. They try to support me." }\end{array}$ \\
\hline Access to and quality of health care & $\begin{array}{l}\text { "Waiting in line for a long time; sometimes the treatment is bad." } \\
\text { "It is good; there is respect and organization. The health care is good." }\end{array}$ \\
\hline $\begin{array}{l}\text { Chronic disease management and } \\
\text { depression }\end{array}$ & $\begin{array}{l}\text { "My chronic disease increases when I'm depressed. I don't take care of myself and this makes my disease } \\
\text { worse." } \\
\text { "When I feel pain in my body, my depression gets worse." }\end{array}$ \\
\hline Female-specific hardships & $\begin{array}{l}\text { "We work inside and outside of the home and no one will help [us]." } \\
\text { "Women get depressed because they are oppressed." }\end{array}$ \\
\hline
\end{tabular}


had been destroyed, they were worried for their children, their husbands had been arrested, women and children had been kidnapped, they lacked access to food, and they were exposed to bombings and warfare. This ongoing stressor of seeking safety was not found among Jordanian participants.

\section{Positive experiences in Jordan}

\section{Syrian}

Although Syrian women shared several stressors, they also reported positive experiences in Jordan: 4 women praised Jordan for its safety, 2 felt at home in Jordan because it reminded them of Syria, and 3 others felt supported in regard to access to education, health services and medication (Table 1).

\section{Stressors influencing depression}

\section{Syrian}

Family: Several stressors impacting depression were found to be Syrian-specific. For example, family as a stressor manifested in different ways: Syrian women feared losing their families in Syria to the war and reported that their husbands had been arrested or killed. One woman shared "In Syria, my husband was arrested for 9 months and he got out wounded and can't work and can't do anything and when they wanted to arrest him again, we escaped."

Unemployment: In addition to familial trauma, 4 women shared that their husband's unemployment in Jordan was a salient stressor given the high cost of rent and daily living expenses. Several women were unable to provide for their children or assist their children in attending university.

Migration: Twelve women discussed how the move from Syria to Jordan itself was a traumatic event: many of them were smuggled into the country illegally. Four of these women had to pay their entire savings to enter Jordan.

\section{Discrimination}

\section{Syrian}

Two Syrian participants shared that they faced discrimination in Jordan. One woman commented, "I used to go to health centres in Madaba and they treated us badly and said mean things, for example that we get medicine from the health centre to sell it" (Table 1).

\section{Jordanian}

Jordanian women did not have migration and minority-related stressors but did face some of the same issues as Syrian women. Four Jordanian women reported feeling lonely, 6 identified stress from economic hardships, 11 reported family and marital problems, and 12 reported health problems as stressors (Table 2). Jordanian women also reported low self-esteem related to their perceived inadequacy in providing for their children and not working.

\section{Perceived social support for depressive symptoms}

\section{Syrian}

Level of social support: Eleven Syrian women felt they could not share their depression with anyone (Table 1). One woman stated, "I don't share [my depression] because we're all depressed." Nine women reported having some form of social support, including talking to sisters, leaving the house and visiting neighbours or female individuals. Only one explicitly stated that her husband supported her emotionally.

Coping mechanisms: Twelve women reported solitary behaviour when experiencing episodes of depression, including sleeping, crying, smoking and not talking to anyone. Three women reported prayer and reading the Quran as helpful coping mechanisms.

\section{Jordanian}

Level of social support: Jordanian women largely reported greater social support than Syrian women: 16 participants received social support from family and friends (Table 2).

Coping mechanisms: Jordanian women reported prayer as a coping mechanism but they also found comfort through solitary activities such as sleeping, sitting alone and crying.

\begin{tabular}{|c|c|}
\hline Theme & Quotation \\
\hline Stressors & $\begin{array}{l}\text { "Losing money or someone I love." } \\
\text { "Thinking about my children's future because I'm alone and my husband is dead and I feel scared." }\end{array}$ \\
\hline Perceived social support & $\begin{array}{l}\text { "My neighbours support me and make me feel better." } \\
\text { "I tell my mother, she is always there for me." }\end{array}$ \\
\hline Access to and quality of health care & $\begin{array}{l}\text { "I don't feel comfortable. I don't get the health care I need. The health care quality is not good." } \\
\text { "It's not very good. I have to stand in line for a long time and the treatment is not very good." }\end{array}$ \\
\hline $\begin{array}{l}\text { Chronic disease management and } \\
\text { depression }\end{array}$ & $\begin{array}{l}\text { "When I find out that there is no solution for my disease I feel sad." } \\
\text { "When I have shortness of breath I feel sad because I can't do routine things." }\end{array}$ \\
\hline Female-specific hardships & $\begin{array}{l}\text { "Men treat her bad; the responsibilities she has to take care of." } \\
\text { "Everyone abandons her; they leave her alone and she's responsible for everything, including her children and } \\
\text { her family." }\end{array}$ \\
\hline
\end{tabular}




\section{Access to and quality of health care}

\section{Syrian}

Nine Syrian women struggled to access affordable medication for their chronic illnesses, which they reported led to depressive spikes due to a perceived lack of control over their lives. Five women commented on long waiting times at clinics, including women who had children with disabilities (Table 1). Five women reported low quality care, and one reported fighting with physicians after feeling like they wanted her to leave. Ten women reported positive experiences with the quality of health care in Jordan.

\section{Jordanian}

Jordanian women expressed more negative experiences with the health care system compared with Syrian women (Table 2). Nine women listed long wait times at primary care centres, and one shared, "It's very difficult and annoying because it's always so crowded and it takes so long and they don't always have my medicine."

\section{Bidirectional relationship between chronic disease and depression}

\section{Syrian}

Seventeen women endorsed a relationship between chronic disease and depression (Table 1). Women shared that at times they feel too depressed to take medication, that their depression caused their chronic illnesses ("Depression caused by our situation in Syria brought us diseases"), or that their chronic illness caused them to feel despondent. One woman believed her husband divorced her due to her cancer, which instigated her depression. Participants also reported stigma in seeking care for their depression: 3 women disclosed receiving a diagnosis of depression, but none of them took antidepressants. One Syrian woman shared, "I didn't take medicine for depression because I didn't like to take it. I didn't like the idea of having depression and having to medicate for it."

\section{Jordanian}

Some Jordanians felt ashamed for experiencing depression. Two women refused to take medication for depression even though they experienced symptoms. As with the Syrian participants, Jordanian women also struggled to take their medication for their chronic illnesses due to their depression (Table 2). One woman shared, "Sometimes I don't take my medicine because I'm depressed. I didn't eat and I slept for a long time." Like the Syrian women, only 2 Jordanian women reported being formally diagnosed with depression. No Jordanian women reported having trouble accessing medication or health services.

\section{Female-specific hardships influencing depression}

\section{Syrian}

Syrian women described gender-specific stressors that at times did not overlap with Jordanian women. Most notably, Syrian mothers feared for their children's safety and also felt a lack of control over their own lives due to their economic situation, not being able to give their children what they need, and "psychological pressure" from demanding husbands (Table 1). Common stressors also faced by Jordanian women included boredom, marital problems, poor treatment from their husbands, presumed gendered differences in emotional processing (for example, believing that women were inherently more emotional than men), as well as laborious household responsibilities such as housekeeping and child rearing.

\section{Jordanian}

As noted in the Syrian overview, Jordanians endorsed a number of gender-specific difficulties including lack of support from others, the demands of motherhood, marital problems and boredom (Table 2).

\section{Discussion}

In this study, we examined the bidirectional relationship between chronic disease and depression among 20 Syrian refugees and 20 Jordanian women, as well as related themes involving rationale for migration, access to and quality of health care, and female-specific hardships impacting mental health. Seeking safety was the primary immigration rationale for the majority of Syrians interviewed. Among our sample, Syrian women praised Jordan for its safety, education and health services. One Syrian woman reported that she preferred Jordan because she felt the government treats Syrians better than the Lebanese government. Compared to neighbouring Lebanon, Jordan has allowed the UNHCR to register Syrians as refugees and permitted the construction of permanent refugee camps such as Zaatari camp (12). In addition, the Jordanian government formalized the entrance of Syrians into the Jordanian labour market in 2016 (13). These differences may have influenced which neighbouring countries Syrians decided to apply to for refugee status.

Additionally, some Syrians reported emigrating to seek medical care in Jordan. This finding is consistent with the literature, with a 2016 household survey showing that $86.1 \%$ of Syrian households sought medical care in Jordan (7). Syrian women reported higher satisfaction with access to and quality of health care compared to their Jordanian counterparts. This may be explained by the fact that Syrian women had no feasible alternatives, whereas Jordanian women recall receiving higher quality care prior to the influx of displaced populations. Despite high levels of health care-seeking behaviour among Syrian refugees, medical costs remain a significant barrier.

The stressors related to depression reported by Syrian refugee women were consistent with previous findings in the Syrian refugee population. In our study, women feared the loss of family members in the war and familial imprisonment in Syria. In addition, many women reported their husband's unemployment and financial problems as major stressors impacting their lives. The relationship between unemployment and financial difficulties has been previously explored (14), and a 2016 
study demonstrated that caring for family members with mental and physical illnesses contributed to increased rates of unemployment among displaced Iraqis (15). Similarly, a 2018 study among Syrian refugees in Jordan found that the most common stressors were related to financial hardship, lack of employment opportunities and income and costly living expenses (16). It has also been demonstrated that financial difficulties, combined with lack of social support, exacerbated psychological stress (17).

Nearly all Syrian and many Jordanian women endorsed a bidirectional relationship between their chronic disease and depression. Some reported that they were too depressed to take their medications and believed that their depression had caused their chronic illness. Others felt despondent due to their chronic ailments. Depression has a significant impact on medication adherence among those with chronic disease, with a depressed individual being almost twice as likely to be non-adherent to their medication regimen compared with a non-depressed individual (18). The bidirectional relationship between chronic and mental illness is complex as depression may cause the direct or indirect worsening of chronic illnesses, which in turn exacerbates the depressive symptoms.

The majority of women in this study felt as though they could not tell others about their depression. A multinational community survey found that women with no social support were more vulnerable than men with no social support when faced with negative life events (19). In collectivist societies like the Syrian community, immediate and extended family play an integral role in providing social support for women. Therefore, Syrian refugee women removed from their social support networks and now living in Jordan are likely more vulnerable to the negative life events that accompany displacement when facing them alone. Another rationale could be that Syrian women feel they must "stay strong" for their families during traumatic events. Less than half of the women reported that they had a sister or female friend in whom they could confide. Low perceived social support has been shown to worsen mental health issues (19).

For physicians and public health practitioners, designing interventions in Jordan for women with chronic diseases and depression differs in line with migration status and exposure to ongoing conflict. Jordan's health care system consists primarily of the public and private sectors, as well as United Nations and nongovernmental agencies. Of the nearly three-quarters of Jordanians who are insured, $80 \%$ have public insurance (20). Around $30 \%$ of Jordanians over age 25 years have at least one chronic disease, with diabetes, hypertension and respiratory illnesses being the most prevalent (20). Many Jordanians receive care from Ministry of Health clinics and large academic hospitals. Expansion of primary and secondary prevention programmes within the public health sector may reduce the development of chronic disease and mental illness among Jordanian women.
The Jordanian population is increasingly comprised of displaced persons. The majority of Syrian refugees in Jordan live in urban, non-camp settings, and nearly a third reside in Amman Governorate (1). Approximately a quarter of Syrian refugees in Jordan are women of childbearing age (1). Until November 2014, the Jordanian government provided free health care to Syrian refugees registered with the United Nations High Commissioner for Refugees (21). After this policy was discontinued, Syrian refugees were required to pay the same costs as non-insured Jordanians. This subsidized rate still represents a considerable financial burden for many displaced persons (22). As a result, refugees frequently seek free or subsidized health care from international nongovernmental clinics.

The protracted Syrian conflict has placed an immense burden on the Jordanian health care system. Chronic illnesses, communicable diseases, mental health issues and injuries remain among the leading causes of morbidity and mortality for both Jordanians and Syrians $(3,21)$. The health challenges faced by Syrian refugees reflect the disease epidemiology of local populations and displaced persons in other communities (21). Health promotion programmes, particularly impactful when aimed at communities at increased risk of adverse health outcomes, should be expanded among Syrian refugees to improve health seeking behaviour and increase health literacy. Health promotion activities rely on intersectoral action, which is appropriate given the governmental, local and international agencies involved in health care for displaced Syrians in Jordan.

A recent study found that two-thirds of Syrian refugees reported financial barriers to accessing health care in Jordan (21). Transportation was one of the most common issues, along with out-of-pocket costs for medications, consultations and procedures (2). In our study, prohibitive medication costs were a recurring theme among Syrians interviewed. Lack of specialist physicians and refusal to provide services have also been cited as barriers to obtaining health care (21). Refugees living in camps have greater access to free or subsidized medical care from international agencies. Governmental policy changes to broaden insurance options for Syrian refugees and increase access to subsidized or free health services, including transportation services for non-camp refugees, are required to address structural barriers to health care access among displaced persons.

Syrian women would also benefit from an expansion of programmes enabling them to interact with women in similar situations. A 2019 study found that Syrian refugee women in Lebanon benefit from community kitchens due to "social cohesion and integration of refugees within host communities in protracted crises contexts" (23). Implementing such a programme among Syrian women in Jordan would be beneficial for both chronic disease management (for example healthy eating) and social support. Mental health care practitioners should be aware of the intersectionality of Syrian female patients with regard to ongoing stressors as women, displaced 
migrants, women with chronic disease, mothers, widows and other salient identities. Primary care providers should be cognisant of the role of migration and depression when treating Syrian women patients in Jordan who have chronic illnesses as these women face different stressors and barriers to adherence to medication and healthy lifestyles compared with Jordanian women with the same diagnoses.

This study has a number of strengths. It goes beyond the descriptive nature of the currently available body of literature on chronic disease and depression among Syrian women and their host community counterparts. The researchers obtained detailed narratives from Syrian women about their journeys to Jordan as well as sensitive stressors in their new country that they largely reported not to have shared with their social network. In addition, the study explored the intersection of exposure to violent conflict, chronic disease management and depression among Arab women, a topic that has not attracted much attention in the literature.

Credibility is comparable to internal validity in qualitative research and establishes whether the findings are a correct interpretation of participant views. In this study, credibility was established through data triangulation - gathering data from 40 Syrians and Jordanians at different sites during different times of day, and investigator triangulation - having multiple investigators involved in coding, analysis and interpretation. Transferability, or the degree to which the results can be transferred to other contexts, was achieved using thick description by describing the context of the Syrian conflict and health care systems accessed by Jordanians and Syrians to better understand the behaviour and experiences of displaced and local women. Dependability, or the stability of findings over time, and confirmability, the degree to which findings are reproducible, are evaluated by audit trail, or by describing the research steps taken from start to finish of this research project in the Methods section.

This study also has several limitations. We used self-reporting instruments in the interview, leading to possible self-report bias. Furthermore, the small sample size may limit the generalizability of these findings. We also employed convenience sampling, a nonprobability sampling method with inherent limitations.

\section{Conclusion}

Chronic disease and depression are primary contributors to morbidity among displaced Syrian and Jordanian women. Examining the intersection of depression and chronic disease among female Syrian refugees and Jordanians provides insight into their respective and shared stressors, experiences accessing health care, coping strategies and female-specific hardships. Such information allows mental health and chronic disease interventions to address similarities and differences among these 2 populations, which may reduce disease burden and disability.

Funding: None.

Competing interests: None declared.

\section{Étude de la relation bidirectionnelle entre maladie chronique et dépression chez les réfugiées syriennes et les Jordaniennes : une analyse qualitative}

\section{Résumé}

Contexte : Près de 700000 réfugiés syriens résident actuellement en Jordanie. Les maladies chroniques et les pathologies neuropsychiatriques sont les principales causes de morbidité dans les communautés de réfugiés et d'accueil. La relation bidirectionnelle entre dépression et maladie chronique n'est pas bien étudiée chez les réfugiées syriennes ou les Jordaniennes.

Objectifs : La présente étude qualitative examine la relation bidirectionnelle entre la maladie chronique et la comorbidité dépressive, ainsi que les thèmes connexes, chez les femmes jordaniennes et syriennes atteintes de maladies chroniques connues - des populations qui reçoivent des soins médicaux par le biais de structures de soins de santé distinctes et évolutives - afin d'aider les prestataires et les responsables de l'élaboration des politiques à mettre au point des interventions culturellement sensibles.

Méthodes : Quarante femmes jordaniennes et réfugiées syriennes atteintes de maladies chroniques ont été interrogées dans quatre services cliniques à Amman (Jordanie). La collecte des données s'est déroulée de juin à août 2017. Dedoose, un logiciel de codage qualitatif a été utilisé pour réaliser l'analyse du contenu.

Résultats : La majorité des Syriennes ont reconnu l'existence d'une relation entre leur maladie chronique et la dépression. Certaines se sont senties trop déprimées pour prendre des médicaments contre les maladies chroniques, tandis que d'autres ont estimé que la dépression contribuait aux maladies chroniques. Les Syriennes ont rapporté un soutien social moins perçu que les Jordaniennes. Même si certaines Syriennes n'avaient pas les moyens de se procurer des médicaments, elles ont signalé moins d'expériences négatives en matière de soins de santé que les Jordaniennes. Les deux populations ont approuvé les difficultés spécifiques aux femmes qui ont un impact sur leur santé mentale, y compris les exigences de la maternité, les tâches ménagères et les conflits conjugaux.

Conclusion : La présente étude examine l'intersection de la dépression et des maladies chroniques chez les femmes syriennes et jordaniennes. En documentant les facteurs de stress et les expériences d'accès aux soins de santé, les interventions en matière de santé mentale et de maladies chroniques peuvent être intégrées et adaptées à ces populations. 


\section{استكشاف العلاقة بين الأمر اض المزمنة والاكتئاب في صفوف الأردنيات و اللاجئات السوريات: تحليل كيفي

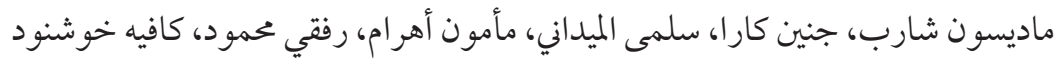

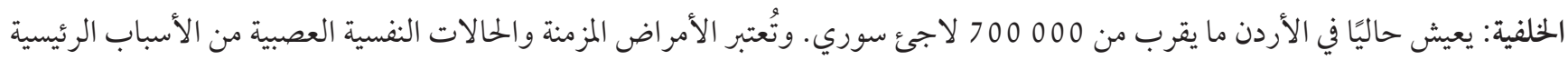

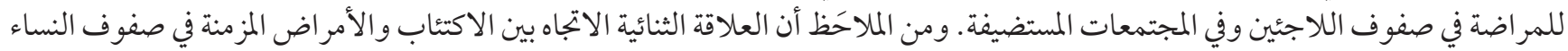

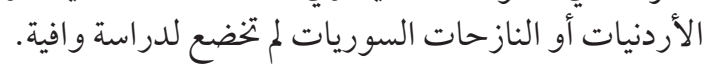

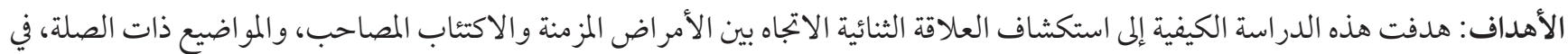

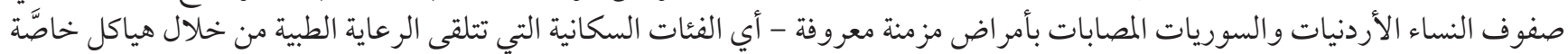

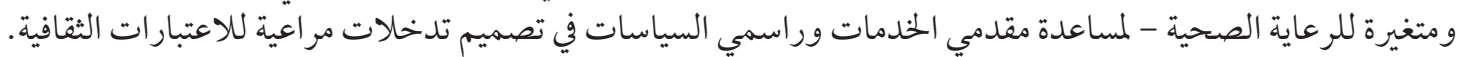

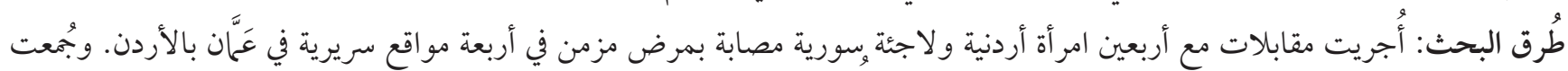

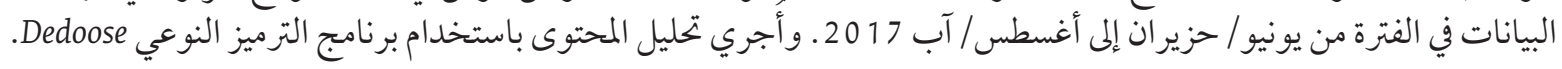

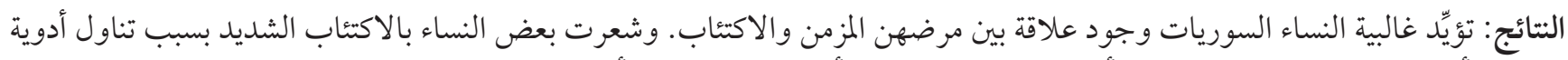

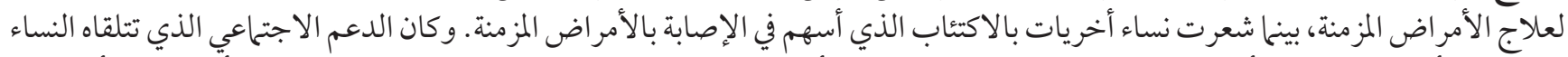

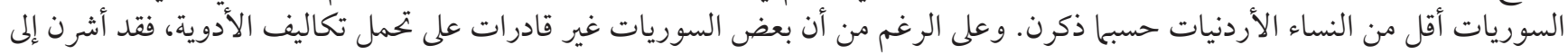

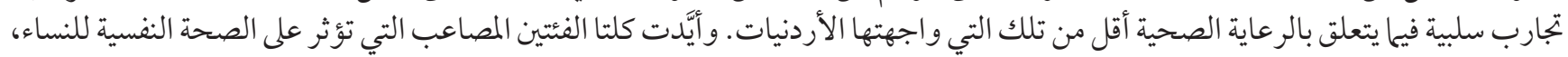

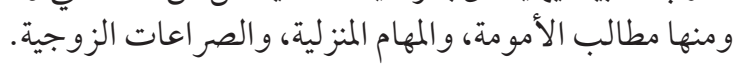

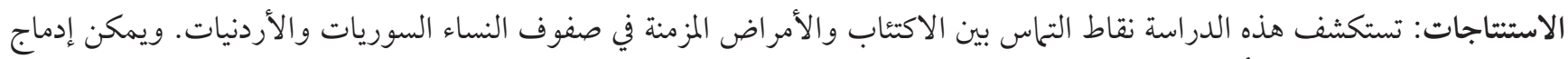

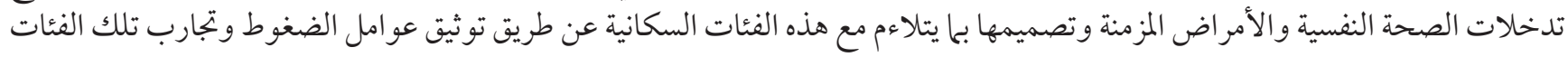
في الحصول على الرعاية الصحية.

\section{References}

1. Operational portal: refugee situations. Syria regional refugee response. Geneva: United Nations High Commissioner for Refugees; 2019 (https://data2.unhcr.org/en/situations/syria/location/36, accessed 7 June 2019).

2. Akik C, Ghattas H, Mesmar S, Rabkin M, El-Sadr WM, Fouad FM. Host country responses to non-communicable diseases amongst Syrian refugees: a review. Confl Health. 2019;13:8. doi:10.1186/s13031-019-0192-2

3. Gammouh OS, Al-Smadi AM, Tawalbeh LI, Khoury LS. Chronic diseases, lack of medications, and depression among syrian refugees in Jordan, 2013-2014. Prev Chronic Dis. 2015 Jan 29;12:E10. doi:10.5888/pcd12.140424

4. Syrian Refugee Health Access Survey in Jordan. Geneva: United Nations High Commissioner for Refugees; 2014 (https://data2. unhcr.org/en/documents/details/45809, accessed 7 July 2020).

5. Al-Nsour M, Zindah M, Belbeisi A, Hadaddin R, Brown D, Walke H. Prevalence of selected chronic, noncommunicable disease risk factors in Jordan: results of the 2007 Jordan Behavioral Risk Factor Surveillance Survey. Prev Chronic Dis. $2012 ; 9:$ :E25. PMID:22172192

6. Al-Krenawi A, Graham JR, Kandah J. Gendered utilization differences of mental health services in Jordan. Community Ment Health J. 2000;36(5):501-11. doi:10.1023/a:1001963714338

7. Doocy S, Lyles E, Akhu-Zaheya L, Burton A, Burnham G. Health service access and utilization among Syrian refugees in Jordan. Int J Equity Health. 2016;15(1):108. doi:10.1186/s12939-016-0399-4

8. Daradkeh TK, Alawan A, Al Ma'aitah R, Otoom SA. Psychiatric morbidity and its sociodemographic correlates among women in Irbid, Jordan. East Mediterr Health J. 2006;12(Suppl. 2):S107-17. PMID:17361682

9. Wells R, Steel Z, Abo-Hilal M, Hassan AH, Lawsin C. Psychosocial concerns reported by Syrian refugees living in Jordan: systematic review of unpublished needs assessments. Br J Psychiatry. 2016;209(2):99-106. doi:10.1192/bjp.bp.115.165084

10. Neuendorf KA. The content analysis guidebook. 2nd ed. Los Angeles: Sage; 2016.

11. Pope C, Ziebland Z, Mays N. Analysing qualitative data In: Pope C, Mays N, eds. Qualitative Research in Health Care. London: BMJ Publishing Group; 1999:75-88.

12. Lenner K, Schmelter S. Syrian refugees in Jordan and Lebanon: between refuge and ongoing deprivation? IEMed Mediterr Yearbook. 2016:122-6.

13. Fakih A, Ibrahim $M$. The impact of Syrian refugees on the labor market in neighboring countries: empirical evidence from Jordan. Bonn: Institute of Labor Economics; 2016 (Discussion Paper No. 9667_. 
14. Paul KI, Moser K. Unemployment impairs mental health: meta-analyses. J Vocational Behav. 2009;74(3):264-82. doi:1016/j. jvb.2009.01.001

15. Wright AM, Dhalimi A, Lumley MA, Jamil H, Pole N, Arnetz JE, et al. Unemployment in Iraqi refugees: the interaction of pre and post-displacement trauma. Scand J Psychol. 2016;57(6):564-570. doi:10.1111/sjop.12320

16. Alfadhli K, Drury J. A typology of secondary stressors among refugees of conflict in the Middle East: the case of Syrian refugees in Jordan. PLoS Curr. 2018:1-22.

17. Grenard JL, Munjas BA, Adams JL, et al. Depression and medication adherence in the treatment of chronic diseases in the United States: a meta-analysis. J Gen Intern Med. 2011;26(10):1175-82. doi:10.1007/s11606-011-1704-y

18. Dalgard OS, Dowrick C, Lehtinen V, Vázquez-Barquero JL, Casey P, Wilkinson G, et al. Negative life events, social support and gender difference in depression. Soc Psychiatry Psychiatr Epidemiol. 2006;41(6):444-451. doi:10.1007/s00127-006-0051-5

19. Grav S, Hellzèn O, Romild U, Stordal E. Association between social support and depression in the general population: the HUNT study, a cross-sectional survey. J Clin Nurs. 2012;21(1-2);111-20. doi:10.1111/j.1365-2702.2011.03868.x

20. Nazer LH, Tuffaha H. Health care and pharmacy practice in Jordan. Can J Hosp Pharm. 2017;70(2):150-5. doi:10.4212/cjhp. v70i2.1649

21. Dator W, Abunab H, Dao-Ayen. Health challenges and access to health care among Syrian refugees in Jordan: a review. East Mediterr Health J. 2018;24(7):680-6. doi:10.26719/2018.24.7.680

22. Health access and utilization survey: access to health services in Jordan among Syrian Refugees. Geneva: United Nations High Commissioner for Refugees; 2017 (https://reliefweb.int/sites/reliefweb.int/files/resources/UNHCR-HealthAccess\%26UtilizationSurveyinJordan2017-Syrians.pdf, accessed 10 July 2020).

23. Ibrahim N, Honein-AbouHaidar G, Jomaa L. Perceived impact of community kitchens on the food security of Syrian refugees and kitchen workers in Lebanon: qualitative evidence in a displacement context. PLoS One. 2019;14(1):e0210814. doi:10.1371/journal.pone.0210814 